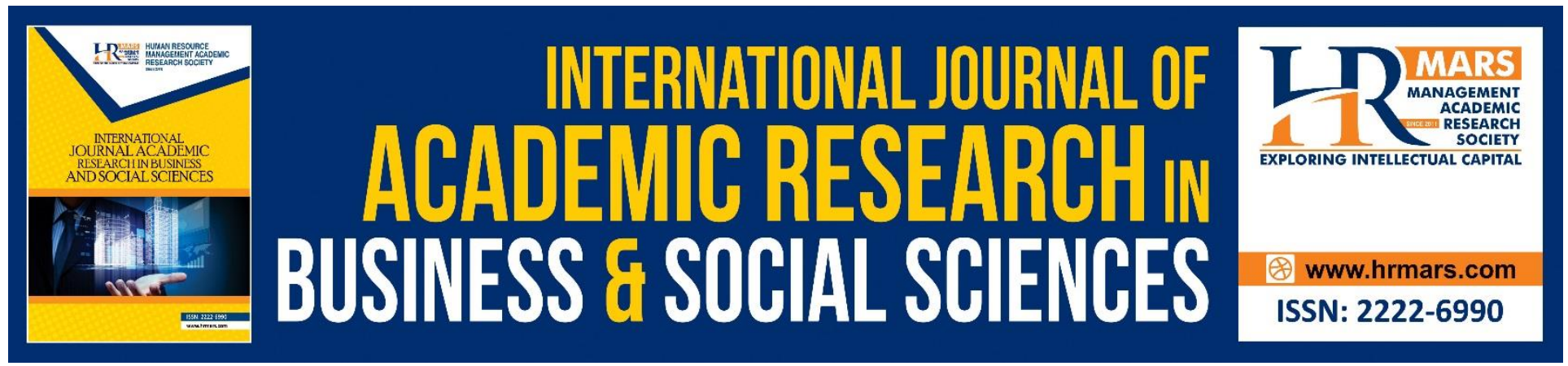

\title{
Selected Theories on the Use of Profanity
}

\author{
S Ashwindren, V Shankar and Nafiseh Zarei
}

To Link this Article: http://dx.doi.org/10.6007/IJARBSS/v8-i9/4876

DOI: $\quad 10.6007 /$ IJARBSS/v8-i9/4876

Received: 15 August 2018, Revised: 07 Sept 2018, Accepted: 29 Sept 2018

Published Online: 04 October 2018

In-Text Citation: (Ashwindren, Shankar, \& Zarei, 2018)

To Cite this Article: Ashwindren, S., Shankar, V., \& Zarei, N. (2018). Selected Theories on the Use of Profanity. International Journal of Academic Research in Business and Social Sciences, 8(9), 1975-1982.

Copyright: (C) 2018 The Author(s)

Published by Human Resource Management Academic Research Society (www.hrmars.com)

This article is published under the Creative Commons Attribution (CC BY 4.0) license. Anyone may reproduce, distribute, translate and create derivative works of this article (for both commercial and non-commercial purposes), subject to full attribution to the original publication and authors. The full terms of this license may be seen at: http://creativecommons.org/licences/by/4.0/legalcode

Vol. 8, No. 9, September 2018, Pg. 1975 - 1982

http://hrmars.com/index.php/pages/detail/IJARBSS

JOURNAL HOMEPAGE

Full Terms \& Conditions of access and use can be found at http://hrmars.com/index.php/pages/detail/publication-ethics 


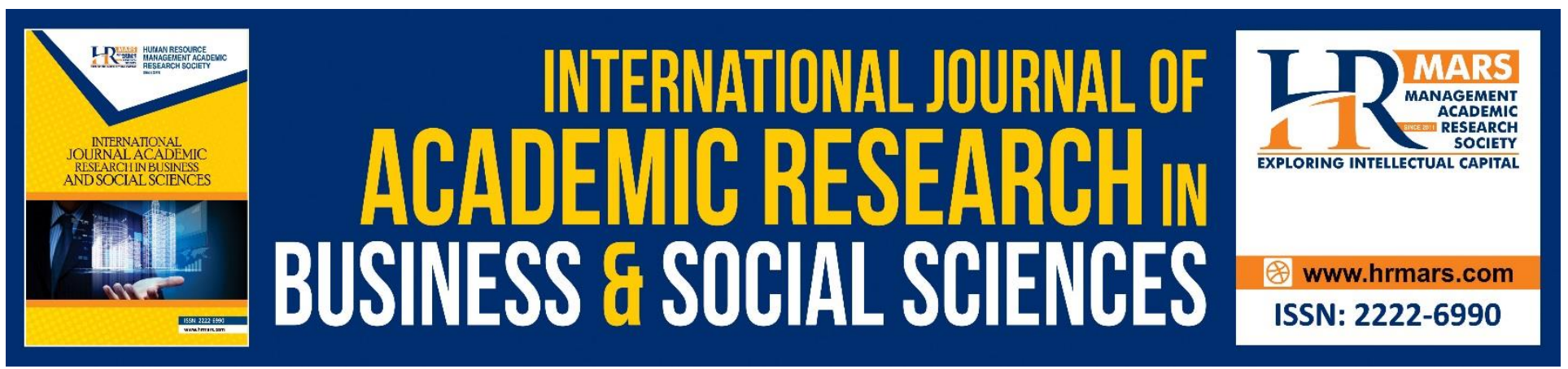

\title{
Selected Theories on the Use of Profanity
}

\author{
S Ashwindren, V Shankar and Nafiseh Zarei \\ UNITAR International University, Malaysia
}

\begin{abstract}
The purpose of this study attempts to discuss selected related theories on profanity and its influence towards the daily communication. It explains and reviews theory of sociolinguistics and selfperception theory with regard to use of profanity in daily communications. Sociolinguistic theory discusses the interconnection between language and society. It also elaborates on how every person uses a language and speaks in a particular way as part of their socio-cultural act. The focus of selfperception theory is on attitude formation developed by psychologist and it emphasizes on the development of people's attitude. In addition, this theory emphasizes that people induce attitudes without accessing internal cognition as well as mood states.
\end{abstract}

Keywords: Profanity, Sociolinguistics, Self-Perception, Communication Skill

\section{Introduction}

It is known that swearing and profanity are commonly used in everyday language by both genders and different age groups. People tend to use profanity to exhibit their feelings in different situations, be it to express joy, sorrow, anger, humour or even surprise. Studies show that it has become a norm for swear words to appear in the conversations of youths. This is often related to the influence of television, movies, games and Internet that tend to expose foul language or swear words to youths on a day to day basis. Jay (1992) mentioned that swearing exists at all age groups. However, the highest swearing among teenagers and as they get older, swearing reduces. Youths tend to spend time talking about sex, practicing sex slang, telling jokes and switching sex-oriented literature. Hence, it is a period of constructing their self-concept. Society also influences their development and impacts on their relationship with their peers and adults. Therefore, a local study on the use of swear words would throw light on the choice of swear words and the pattern of use among their peers.

Besides that, profanity also refers to the use of obscene language including taboo and swear words, which in regular social settings are considered inappropriate and in some situations unacceptable. It often includes sexual references, blasphemy, objects eliciting dis- gust, ethnicracial-gender slurs, vulgar terms, or offensive slang (Mabry, 2008). The interest in understanding the psycho- logical roots of the use of profanity dates back to as far as the early 20th century, yet the literature in this domain is scattered across different scientific fields with only recent attempts to connect the findings into a unified frame- work (Jay, 2009). 
The reasons for using profanity depend on the person and the situation, yet profanity is commonly related to the expression of emotions such as anger, frustration, or surprise (Jay and Janschewitz, 2008). The spontaneous use of profanity is usually the unfiltered genuine expression of emotions, with the most extreme type being the bursts of profanity (i.e., coprolalia) accompanying the Tourette syndrome (Cavanna and Rickards, 2013). The more controllable use of profanity often helps to convey world views or internal states or is used to insult an object, a view, or a person (Jay, 2009).

Speech involving profane words has a stronger impact on people than regular speech and has been shown to be processed on a deeper level in people's minds (Jay and Caldwell-Harris,King, 2008). The context is important for understanding profanity. Profanity can sometimes be interpreted as antisocial, harmful, and abusive if, for example, intended to harm or convey aggression and hostile emotions (Stone, McMillan, \& Hazelton, 2015). It also violates the moral foundations of purity (Sylwester \& Purver, 2015) and the common norm for speech, suggestive of the potential to engage in other antisocial beha- viors that violate norms and morality. However, profanity may also be seen as a positive if it does not inflict harm but acts as a reliever of stress or pain in a cathartic effect (Vingerhoets, Bylsma, \& de Vlam, 2013).

\section{Theory of Sociolinguistics}

Sociolinguistics is the study about language that is related to society that the language related with the use of the languages spoken by society in the habit. According to Holmes (1992:1) sociolinguistics is the study that has relationship with language and society in the world. It is in line with Fasold's (1993) idea about sociolinguistics which is science that combine linguistic and society. Brown (2000) also believes that sociolinguistics is sub-discipline of linguistic which examines the relationship between language and culture as well as language and society.

According to Wardhaugh (2011), sociolinguistics is concerned with investigating the relationships between language and society with the goal of having a better understanding of the structure of language. Moreover, it focuses on how languages function in communication and the equivalent goal in the sociology of language which is to discover how social structure can be better understood through the study of language. For instance, how certain linguistic features serve to characterize particular social arrangements. In others argument, based on Hudson's opinion in Wardhaugh (2011), sociolinguistics is the study of language in relation to society, whereas the sociology of language is the study of society in relation to language.

Language is fundamental to social interaction in all societies. In other words, the relationship between language and society is intertwined. The way people use language in different social context produces different jargons and this will vary for different layers of society. The different layers of the society include age, gender, and cultural groups. According to Fairclough (2001), a critical awareness of language arises within the normal ways people reflect on their lives as part of their lives. In addition, he stated that it is vital to understand how the language functions and to think of it in different ways in order to understand the society. The theory is applied as the basic understanding to analyze the data in order to answer research questions one and three of the study. By understanding how language and society goes coherent, it will be easier for the researcher to understand how students associate the use of their languages and the society that they are part of. 
The choice of language and its use depends on ethnicities, social class, context, gender, and age (Baron, 2005). Therefore, language can vary according to the social structure of its local speech community. As such, language can also be used to express group identity and often regarded as a salient identity factor. This study helps to further understand the choice of language in specific of profane words used by the teenagers in social class that would help to classify research question one that would narrow down the choice of profane words used by them.

Language can serve various functions. Language must be investigated in terms of its own functions. There are six aspects in functions of language to fulfil a successful communication. There must be an addresser who is the sender and an addressee who is the receiver. There must also be a medium of communication which can be verbal, written or visual for the message to be communicated. The medium chosen will influence on how the message is encoded. The addresser and the addressee must have contact to the code. The message that is sent, will be received in a particular context. There are six factors that determine the different functions of language. According to him the functions of language are emotive, referential, conative, phatic, connotation, and metalingual functions. The emotive function serves to display the direct expression of the speaker towards the topic spoken. The referential function of language is where the speaker shares information on knowledge. The conative function of language helps to illustrate the message that intends to have effect on the audience such as to insult or persuade which serves as a point to comprehend research questions two and three in the teenagers' perceptions and their reasons for the function of using such language.

The phatic function serves to communicate about something that is socially acceptable as in small talk. The connotation function is to address someone using imperatives. The metalingual function is important for successful communication. When rephrasing or repeating a message, the metalingual function of language is used. All these functions are important in understanding how people use language to convey messages and meanings. It can be used not only to refer to things but also to demonstrate status and power.

\section{Self-perception Theory}

Self-Perception Theory is an account of attitude formation developed by psychologist (Bem, 1981). It asserts that people develop their attitudes when there is no previous attitude due to a lack of experience and the emotional response is ambiguous by observing their own behavior and concluding what attitudes must have caused it. SPT is counterintuitive in nature, as the conventional wisdom is that attitudes determine behaviours. Furthermore, the theory suggests that people induce attitudes without accessing internal cognition and mood states. The person interprets their own overt behaviours rationally in the same way they attempt to explain others' behaviours.

Philosophers and others have been talking about the self since the advent of written history and modern day theories of self-perception have their roots in historical conceptions of the self (Pajares \& Schunk, 2002). Arguably, the most influential of these is that presented by James in his seminal book Principles of Psychology (James, 2013). He distinguished between the ' $\mathrm{l}$ ' self (or the selfas-knower) and the 'Me' self (or the self-as-known). The ' $\mathrm{l}$ ' is the active thinking processor. The self that is doing all the thinking and living, the self that is the seat of experience and is a core construct within the person. The ' $M e^{\prime}$ is the self as an object one can think about and reflects the structure of 
INTERNATIONAL JOURNAL OF ACADEMIC RESEARCH IN BUSINESS AND SOCIAL SCIENCES Vol. 8, No. 9, Sept. 2018, E-ISSN: 2222-6990 @ 2018 HRMARS

experience. James saw the 'Me' the known-self as being comprised of many 'Me's' or 'constituents' which together reflect a person's overall self-evaluation or self-concept. These constituents include the material self, the social self, the spiritual self, and the pure ego. James saw these as being arranged in a hierarchy according to their worth.

The material self was seen as the least precious, the social self more so, the spiritual self even more so, and the pure ego personal identity as the most precious of all. The material and social selves are comprised of multiple material and social selves. Associated with these selves are the feelings and emotions they arouse (self-feelings), the actions they prompt (self-seeking: providing for the future as opposed to maintaining for the present), and self-defence (or self-preservation). The 'Me' therefore reflects a sense of self which is formed from our various experiences, social encounters, and environmental interactions. The theory helps to comprehend the understanding of the second research question of the present study which seeks to explore the perception of Malaysian teenagers towards using profane words.

In essence, it is considered self-esteem as the ratio of an individual's actualities or achievements to their potentialities (or expectations, i.e. their hopes, desires and aspirations) which could be improved by increasing successes, avoiding failures or, in the face of failure, by lowering expectations (Baldwin \& Hoffman, 2002; Emler, 2001; Mruk, 2006). The researcher therefore defined self-esteem and self-concept in terms of action that is "successful" or "competent".

Self-perception comes from one's experiences. "One of the most important beliefs that influences one's self-leadership capability in their own ability to carry out a task. One's state of mind about yourself clearly impacts your ultimate performance. For most people, self-perception plays a greater role as they get older which is strongly relatable to children as they are becoming a teenagers.

Older people have learned and practiced how to be open to the ideas of others; they are okay with being wrong; they are not attached to particular out-comes; and they have learned how to be good listeners. Since they have gained confidence through life experiences, reflected appraisals and social comparison are no longer very important. Instead, they look at themselves from the point of view of the experiences they have had. For example, parents might consider their lives to have been worthwhile because of you and your siblings. This can be associated between people and language where their use of experience in speaking the language to perceive their self judgement. The teenager's perceptions towards the use of profane words in the context of this study would help answer the second research question.

\section{Consequences of Sociolinguistic Theory and Self-perception Theory}

A speaker is influenced by the choice of profane words use which are words that roll easiest off the tongue and their notions of taboo and perceived rudeness but also possibly by their sociolinguistic, or demographic, background. Factors like gender, age, social class, education, and religion, may have a small or big impact on the particular use of profane words by an individual. These factors may not only influence their language use in general, but also their choices of vocabulary; regional, ethnic, political, and class differences by a diversity of pragmatic norms as they are by linguistic variations' (Thomas, 1991, p. 91).In this subsection, sociolinguistic factors that may be of influence on the profane choices of native Dutch speakers will be discussed and considered both in relation to swearing in general as well as to the choice of language while swearing. However, one 
INTERNATIONAL JOURNAL OF ACADEMIC RESEARCH IN BUSINESS AND SOCIAL SCIENCES Vol. 8, No. 9, Sept. 2018, E-ISSN: 2222-6990 @ 2018 HRMARS

should keep in mind that these speakers are not simple compositions of sociological factors; "a person is not simply female or male, child or adult, employer or worker" (Bonvillain, 1993, p. 4). This study investigates the reasons why teenagers use profane words as it is stated in the third research question. The sociolinguistic theory will be applied as the basic understanding to analyse the problem.

The following sections present the variables that affects choice of language use in the society which are context, domain, age, and ethnicity. Context refers to a concept used in language science. It is divided into verbal context and social context. According to Mercer (2002), context is defined from a sociocultural perspective as socially constructed frames of reference. People use both contexts in their daily lives to communicate effectively and without offending others in the society.

The verbal context refers to words, sentences, conversational turns, and speech acts, which influence the way that the spoken meanings can be understood. However, social context is defined in terms of social variables such as: class, race, and gender. Russell (2011) suggests that context is a weaving together with other people and it is a tool into a web or network of socio-cultural interactions and the meanings which are integral to learning. Social context shapes the actions, thoughts, and feelings of a person. Hence, the gender, race, and status of the speaker influence the language used in term of context. In order to have accurate and valid findings, one has to take into account both verbal and social contexts in this study. This would aid in a deeper understanding based on research question three in this study to evaluate the reasons why teenagers swear or use profanity in social context or in cultural interaction.

Research incorporating self-perception theory has continued in recent years, appearing in conjunction with studies dealing with terrorism, mind wandering, and the inclusion of others in the self. Guadagno et al (2010) and her fellow experimenters carry out a study to address the recruitment of new members by terrorist organization via the internet. In addition to looking at how such an organization might influence its targets to support more extreme ideologies primarily through simple requests gradually increasing to larger commitments-an example of the foot-in-the-door technique, the authors looked at how "the new converts may form increasingly radical attitudes to be consistent with their increasingly radical behaviour. SPT then, has strong ties to social identity and social influence in this scenario however the present study looks into the social communication of teenagers in their use of profanity.

Critcher \& Gilovich (2010) performed four studies to test a connection between selfperception theory and mind wandering. SPT posits that people determine their attitudes and preferences by interpreting the meaning of their own behaviour. Critcher and Gilovich looked at whether people also rely on the unobservable behaviour that is their mind wandering when making inferences about their attitudes and preferences. They found that having the mind wander to positive events, to concurrent as opposed to past activities, and to many events rather than just one tends to be attributed to boredom and therefore leads to perceived dissatisfaction with an ongoing task. Participants relied on the content of their wandering minds as a cue to their attitudes unless an alternative cause for their mind wandering was brought to their attention. However, the focus of the present study is on self-perception and language.

Similarly, (Goldstein \& Cialdini, 2007) published work related to self-perception theory. In an extension of self-perception theory, the authors hypothesized that people sometimes infer their own attributes or attitudes by "observing the freely chosen actions of others with whom they feel a sense 
INTERNATIONAL JOURNAL OF ACADEMIC RESEARCH IN BUSINESS AND SOCIAL SCIENCES Vol. 8, No. 9, Sept. 2018, E-ISSN: 2222-6990 @ 2018 HRMARS

of merged identity almost as if they had observed themselves performing the acts." Participants were made to feel a sense of merged identity with an actor through a perspective-taking task or feedback indicating overlapping brainwave patterns. Participants incorporated attributes relevant to the actor's behaviour into their own self-concepts, leading participants to then change their own behaviours. The study addresses the self-expansion model, close relationships can lead to an inclusion of another person in an individual's sense of self. The study looks into the actor and their perception meanwhile the present study aims at teenagers in Malaysia of their use towards profanity in daily communication.

\section{Conclusion}

Sociolinguistic theory speaks of the interconnection between language and society. A part of it elaborates on how every person uses a language and speaks in a particular way as part of their socio-cultural act. Each students speak in different ways. Self-Perception Theory is about of attitude formation developed by psychologist and It argues that people improve their attitudes when there is no previous attitude because of shortage of experience. In addition, this theory emphesise that people induce attitudes without accessing internal cognition as well as mood states.

\section{Corresponding Author}

S Ashwindren, UNITAR International University, Malaysia

Email:ashwin180793@gmail.com

\section{References}

Baldwin, S. A., \& Hoffman, J. P. (2002). The dynamics of self-esteem: A growth-curve analysis. Journal of Youth and Adolescence, 31(2), 101-113.

Bonvillain, N. (1993). Language, culture, and communication: The meaning of messages. Englewood Cliffs: Prentice Hall

Baron, N. S. (2005). Instant messaging and the future of language. ABOUT, 719.

Bem, S. L. (1981). Gender schema theory: A cognitive account of sex typing. Psychological review, 88(4), 354.

Brown H. Douglas, (2000). Principles of Language Learning and Teaching, Fourth Edition, Longman. Cavanna, A. E., \& Rickards, H. (2013). The psychopathological spectrum of Gilles de la Tourette syndrome. Neuroscience \& Biobehavioral Reviews, 37(6), 1008-1015.

Critcher, C. R., \& Gilovich, T. (2010). Inferring attitudes from mindwandering. Personality and Social Psychology Bulletin, 36(9), 1255-1266.

Emler, N. (2001). Self-esteem: The costs and causes of low self-esteem. York, UK: York Publishing Services for the Joseph Rowntree Foundation.

Fairclough, N. (2001). The discourse of new labour: Critical discourse analysis. Discourse as data: $A$ guide for analysis, 1, 229-266.

Fasold, R. (1993). The Sociolinguistics of Society. Oxford: Blackwell Publishers.

Goldstein, N. J., \& Cialdini, R. B. (2007). The spyglass self: a model of vicarious self-perception. Journal of personality and social psychology, 92(3), 402. 
INTERNATIONAL JOURNAL OF ACADEMIC RESEARCH IN BUSINESS AND SOCIAL SCIENCES Vol. 8, No. 9, Sept. 2018, E-ISSN: 2222-6990 @ 2018 HRMARS

Guadagno, R. E., Lankford, A., Muscanell, N. L., Okdie, B. M., \& McCallum, D. M. (2010). Social influence in the online recruitment of terrorists and terrorist sympathizers: Implications for Social Psychology Research. Revue internationale de psychologie sociale, 23(1), 25-56.

Holmes, J. (1992), An Introduction to Sociolinguistics. London: Longman (p.1).

James, W. (2013). The principles of psychology. Read Books Ltd.

Jay, T. (1992). Cursing in America: A psycholinguistic study of dirty language in the courts, in the movies, in the schoolyards and on the streets. Amsterdam, the Netherlands.

Jay, T., Janschewitz, K. (2008). The pragmatics of swearing. Journal of Politeness Research. Language, Behaviour, Culture, 4, 267-288.

Jay, T. (2009). The utility and ubiquity of taboo words. Perspectives on Psychological Science, 4, 153161.

Jay, T., Caldwell-Harris, C., King, K. (2008). Recalling taboo and nontaboo words. The American Journal of Psychology, 121, 83-103.

Mabry, L. (2008). Case study in social research. The SAGE handbook of social research methods, 214227.

Mercer, N. (2002). Words and minds: How we use language to think together. Routledge.

Mruk, C. J. (2006). Self-esteem research, theory, and practice: Toward a positive psychology of selfesteem (3rd ed.). New York: Springer Publishing.

Pajares, F., \& Schunk, D. H. (2002). Self and self-belief in psychology and education: A historical perspective. Improving academic achievement: Impact of psychological factors on education, 3-21.

Rickford, John R. (2001), Style and stylizing from the perspective of a non autonomous Sociolinguistics. In Style and Sociolinguistic Variation, (ed.).

Russell, L. (2011). Understanding Pupil Resistance-Integrating Gender, Ethnicity and Class: an Educational Ethnography. E \& E Publishing.

Stone, T. E., McMillan, M., \& Hazelton, M. (2015). Back to swear one: A review of English language literature on swearing and cursing in Western health settings. Aggression and violent behavior, 25, 65-74.

Sylwester, K., Purver, M. (2015). Twitter language use reflects psychological differences between democrats and republicans.

Thomas, M. (1991). Universal grammar and the interpretation of reflexives in a second language. Language, 211-239.

Vingerhoets, A. J., Bylsma, L. M., \& De Vlam, C. (2013). Swearing: A biopsychosocial perspective. Psihologijske teme, 22(2), 287-304.

Wardhaugh, R. (2011). An introduction to sociolinguistics (Vol. 28). John Wiley \& Sons. 